\title{
The knowledge domain of chain and network science
}

EDITORIAL

\author{
Onno Omta, Jacques Trienekens and George Beers
}

\begin{abstract}
This editorial paper aims to provide a framework to categorise and evaluate the domain of Chain and Network Science (CNS), and to provide an envelope for the research and management agenda. The authors strongly feel that although considerable progress has been made over the past couple of years in the development of the CNS domain, a number of important and exciting challenges are still waiting to be tackled. This paper provides a definition of the object of study of CNS, its central problem area, the organisation and governance of chain and network co-operation, and the relationships between chain organisation and technology development, market dynamics, and the economy and society at large. It indicates relevant sources of knowledge among the various academic disciplines. It touches upon CNS problem solving by identifying areas for knowledge development and CNS tool construction.
\end{abstract}

Key words: chains, networks

\section{Introduction}

A wide range of trends in technology and society drive public and private actors into new patterns of collaboration. On the technological side, the increasing knowledge content of products and services, and the need to accelerate the pace of product and process innovation, force both public and private parties to specialise, outsource and co-operate. On the socio-economic side, mass-individualisation and accelerating market dynamics foster world-wide competition. Increasing public demands for transparency and accountability call for limitation of negative externalities of socio-economic processes. No single organisation is able to satisfy all these rapidly emerging and entangled demands on its own. As a consequence, value transformation processes in which institutional boundaries become increasingly blurred gradually replace traditional patterns of market transactions. Better understanding of the principles underlying actor-networking and network governance should therefore considered to be a mission of paramount significance for multidisciplinary research.

Chain and Network Science (CNS) is the knowledge domain related to the analysis, construction, governance and validation of chains and networks (e.g. Omta et al., 2001). CNS develops on the basis of practical experiences in chain and network engineering (inductively), and on the basis of theory-inspired research work (deductively), drawn from academic knowledge developed within various disciplines, such as sociology, economics and technology. This editorial paper intends to provide a knowledge map, a tool for directing and focusing CNS research. As such, it tries to clarify what the field of CNS includes, to investigate where we stand in developing CNS and to present a research and management agenda of challenging themes and goals for the years to come.

\section{The object of study of CNS}

The object of CNS entails the ensemble of actors that, through a pattern of related activities, produce and transfer value objects, such as products, services, labour, information, money, and property titles. These activity patterns may be referred to as the chain and network processes, the value objects that flow through the network as the network flows, and the pattern of inter-actor relations as the network structure (Jonkers et al., 2001). This includes their modes of competition and co-operation, and the mechanisms implemented for governance and management of these processes. In particular, CNS concentrates on the behavioural and social aspects of organisation and governance: the nature of choices being made, the incentives and constraints, the basis and the use of power in relationships, and the nature of interaction and communication. Below we will first elaborate on the different chain and network definitions and concepts. Then we will combine these in the netchain approach.

\section{Chains}

Firms pursue their objectives (e.g. market share, stability, growth, and profit-making) given the available resources, technological opportunities and environmental conditions. They seek co-operation in chains if this improves performance levels compared to spot market operations. Together, they organise and govern the consecutive steps from raw materials and intangible inputs to consumer products and services. The various definitions of the supply chain emphasise this flow of value between organisations. We will quote two: 
A supply chain is a system whose constituent parts include material suppliers, production facilities, distribution services and customers, linked together via the feed-forward flow of materials and the feedback flow of information and financial capital. (Stevens, 1989).

A supply chain is a network of organisations that are involved through upstream and downstream linkages in different processes and activities that produce value in the form of products and services in the hands of the ultimate consumer (Christopher, 1998).

Both definitions emphasise that a product is transferred between firms before it reaches the consumer; thus a chain of firms transacting with each other is built. Figure 1 depicts a typical supply chain (Lambert and Cooper, 2000). It shows that SCM views a company in the centre of a network of suppliers and customers. Major characteristics of a supply chain are (Cooper et al., 1997):

- It evolves through several stages of increasing intra- and inter-organisational integration and co-ordination; and spans from initial source (supplier's supplier, etc.) to ultimate consumer (customer's customer, etc.).

- It potentially involves many independent organisations. Thus, managing intra- and inter-organisational relationships is of essential importance.

- It includes the bi-directional flow of products (materials and services) and information, and the associated managerial and operational activities.
- It seeks to fulfil the goals of providing high customer value with an appropriate use of resources, and building competitive chain advantages.

\section{Networks}

Firms may co-operate across markets and across industries in order to leverage their key resources in new areas, exploiting increased economics of scale and scope in those resources. Relationships with other firms that were previously not possible due to high co-ordination costs or high transaction risks may thus become feasible (Clemons and Row, 1992). This may result in a specialisation among actors, leading to increasing interdependence, flattening of hierarchies and the development of inter-firm structures for co-operation and decision-making. Wasserman and Faust (1994, p.20) define a network as:

a finite set or sets of actors and the relation or relations defined on them.

Important is the reciprocal character of the relationships between the actors. Powell (1990) describes a network as a mode of resource allocation where:

transactions occur neither through discrete exchanges nor by administrative fiat, but through networks of individuals engaged in reciprocal, preferential, mutually supportive actions. [...] Basic assumption of network relationships is that one party is dependent

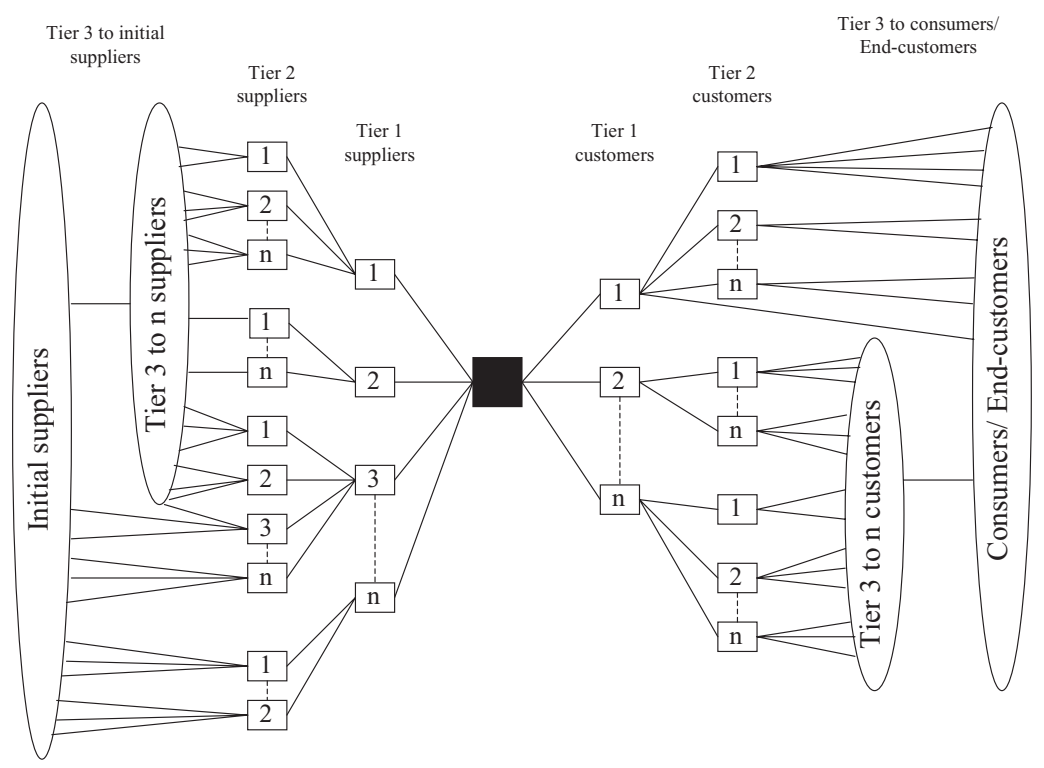

Focal Company

Members of the Focal Company's Supply Chain

Figure 1. Supply chain structure (Lambert and Cooper, 2000). 
on the resources controlled by another, and that there are gains to be had by the pooling of resources. In essence, the parties to a network agree to forgo the right to pursue their own interests at the expense of others.

Sawhney and Parikh (2001) describe how, in the digital economy, intelligence becomes fluid and modular. Companies may build flexible alliances in which capabilities and resources are temporarily combined to react to market opportunities. If these temporary alliances become common, this may lead to value shifts from entities that own intelligence to entities that orchestrate the flow and combination of intelligence. They distinguish four value trends in networks:

- Value at the ends. Most economic value will be created at the ends of networks. At the core - the end most distant from users - generic, scale-intensive functions will be consolidated. At the periphery - the end closest to users - highly customised connections with customers will be made

- Value in common infrastructure. Elements of infrastructure that were once distributed among different machines, organisational units, and companies will be brought together and operated as utilities.

- Value in modularity. Devices, software, organisational capabilities, and business processes will increasingly be restructured as well-defined, self-contained modules that can be quickly and seamlessly connected with other modules. Value will lie in creating modules that can be plugged into as many different value chains as possible.

- Value in orchestration. As modularisation takes hold, the ability to co-ordinate among the modules will become the most valuable business skill.

Network Analysis (NA) looks at the character and organisation of these formal and informal network relationships. In NA the ability of a company to create value is highly dependent on its network position.

\section{Netchains}

Both supply chains and networks are sets of organisations that maintain relationships of some kind. A supply chain is characterised by the sequential order of the transactions involved. The network is characterised by the specific properties of the transaction relationships, typified by reciprocal relationships in which informal information sharing and trust building mechanisms are crucial. Thus the distinguishing characteristics of chains and networks are of a different order. Consequently, a supply chain is not necessarily a network. A supply chain can be considered a network if the sequence of transactions between firms is not only arranged by means of the market or through formal mechanisms, but also by reciprocal and informal mechanisms. Precisely because this is increasingly the case in many supply chains, there is a need to bring insights from Supply Chain Analysis (SCA) and Network Analysis (NA) together.

In the first issue of this journal, Lazzarini et al. (2001) attempt to integrate both lines of thought by relating the difference between SCA and NA to differences in interdependencies between firms or agents. They follow Thompson (1967) in differentiating between sequential interdependencies, which refer to sequentially structured tasks, and pooled interdependencies, which refer to situations where each actor makes a discrete independent contribution to a given task, or reciprocal interdependencies, where such contributions are mutually dependent. They posit that SCA focuses on sequential interdependencies and NA deals primarily with either pooled or reciprocal interdependencies. By relating the differences between SCA and NA to the nature of interdependencies between organisations, they construct a formal basis for integrating them in what they call a netchain approach. They define a netchain as:

a set of networks comprised of horizontal ties between firms within a particular industry or group, such that these networks (or layers) are sequentially arranged based on the vertical ties between firms in different layers.

The combination of certain actors and rules results in a certain type of 'netchain architecture'. Optimising this architecture and the intensity of co-operation may generate added value. Lazzarini et al. (2001) identify six core sources of value improvement resulting from optimising cooperation. The first three of these are related to chain cooperation and the latter three to network co-operation. They focus on the following issues of optimisation: transformation, transaction, property rights and value capture, social structure, network learning, and network externalities.

Though each of these six issues of optimisation has received extensive attention in the literature, this has been predominantly in the context of partial analyses. CNS aims to bring these strands of literature together in an integrative framework. The next two sections draw upon a position paper for the Dutch Chain, Logistics and ICT (KLICT) programme by Diederen and Jonkers (2001). 


\section{The focus of CNS}

Diederen and Jonkers (2001) introduce a descriptive model for CNS. The focus areas of their model are presented in figure 2 .

Below we will discuss the different aspects of CNS separately.

\section{CNS and technology}

Chain organisation, institutional arrangements and technology are interdependent. On the one hand, a different way of organising a chain or network may introduce new requirements or new opportunities in the field of production, logistics, packaging, or storage. On the other hand, technology development may induce changes in the patterns and modes of transactions. A well-known example of technology deployment is the application of information and communication technology (ICT) in inter-company collaboration. ICT can alter and improve inter-company transaction processing, logistics, product design, and intercompany linkages of competencies and capabilities (e.g. Venkatraman, 1994). Of major importance is also the introduction of biotechnology, which may require an entirely different organisation of the value chain with concomitant changes in institutional mechanisms. Producing products with biotechnology may introduce new functions in chains and networks, while making others superfluous; it may increase the value of some production factors (e.g. knowledge, technological capabilities) at the expense of others (e.g. capital equipment, land). It is broadly recognised that new technologies do not come to us as 'manna from heaven'. In technology development both technology-push and demand-pull factors play an important role. This is the subject of extensive literature (e.g. Freeman, 1990 and Stoneman, 1995 for reviews). As CNS focuses on changes in the organisation of value creation, technological innovation, in the sense of adaptation of specific applications of new technologies to the needs of particular chains and networks, is considered an important object of study.

\section{CNS and market dynamics}

Ultimately, firms produce for consumers. What products and services constitute value in the eyes of consumers and what consumers are willing or even eager to buy, depends on the developments of tastes on the one hand, and purchasing power on the other. Though levels of purchasing power are generally beyond the direct influence of firms, tastes for particular products may be influenced through agile marketing. Nevertheless, CNS takes general changes in tastes and levels of income as given, as they are determined by social processes beyond the scope of the individual supply chain or industry network. Higher average levels of income in combination with market saturation for many products have resulted in the transformation of supplydriven markets into demand-driven markets. This results in the need for increased responsiveness and flexibility of

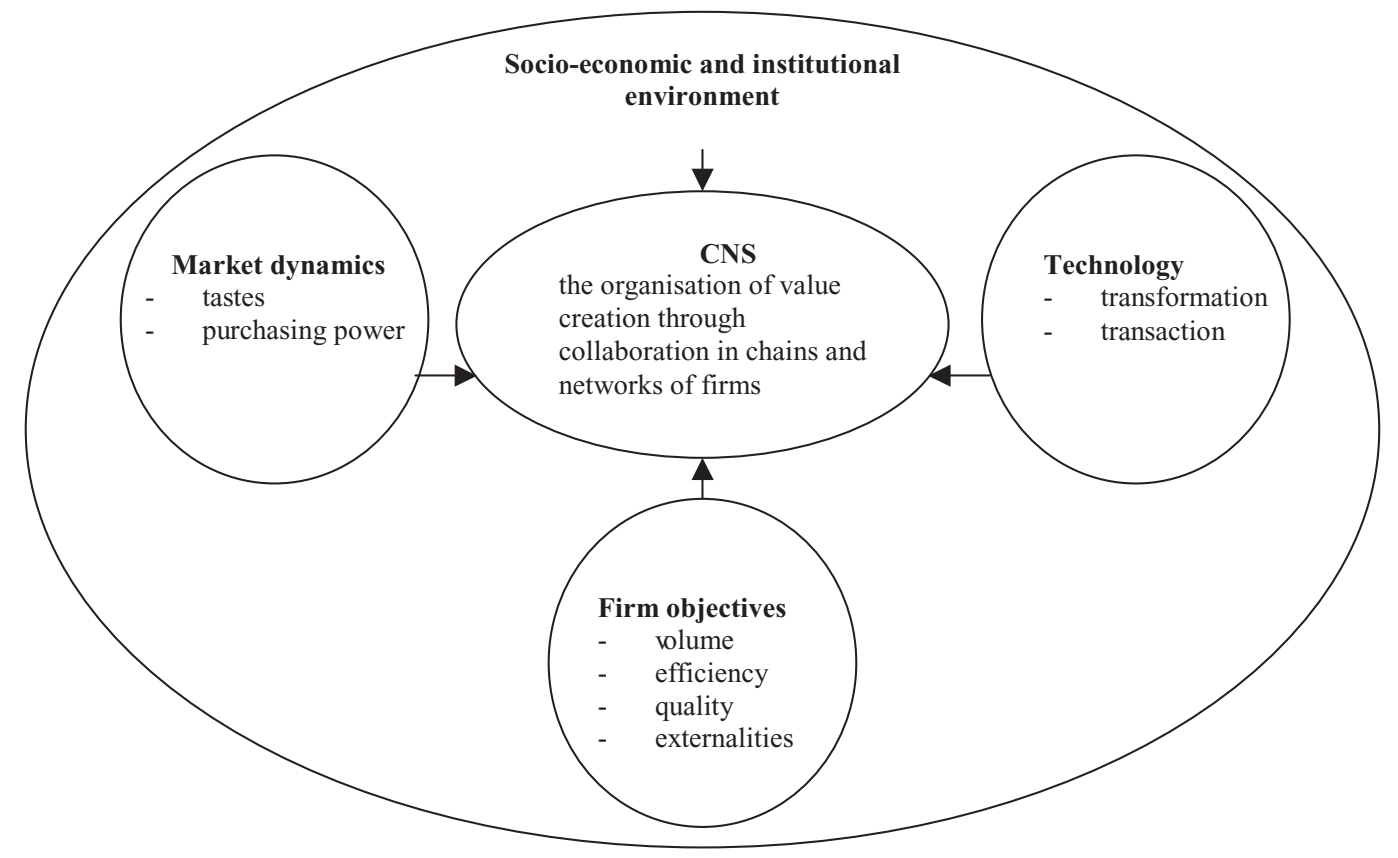

Figure 2. The focus of CNS. 
production, distribution and product development systems, e.g. through introduction of new organisational and technical mechanisms for feedback in production planning, intensified communication, systems of late conversion and postponed production, and improved transparency. Cultural change and mass individualisation result in an increasing demand for product and service differentiation and henceforth in transitions of economies of scale to economies of scope for producers and retailers.

\section{CNS and the institutional and socio-economic environment}

Firms operate in a given socio-economic environment, characterised by product-market structures, labour markets, capital markets and economic policy. Like technological change, institutional change and changes in economic policy are not autonomous processes; they are induced by economic and social dynamics. World-wide economic integration and lowering of international barriers to trade increase global competition. This results in a drive for accelerated technical and organisational innovations to improve efficiency and quality.

\section{Sources of CNS knowledge}

To understand the dynamics of chain and network organisation and the use of institutional mechanisms, inspiration can be obtained from a range of disciplines. Table 1 provides an overview of relevant fields of knowledge (Diederen and Jonkers, 2001). The first two columns list theories that pertain to the core of CNS, chain and network organisation; the latter three columns list theories that concern the links between the core of CNS and the determining factors.

Consequently, CNS is a multidisciplinary endeavour: it draws upon a fairly wide range of social sciences and occasionally makes use of technical inputs. However, CNS aims not only to bring various disciplines together, but also to take the endeavour one step further. It tries to go beyond analysing specific institutions from a single perspective, and to shed some light from an integrative perspective, which institutions are appropriate or optimal in what situation, and on how different institutions interact.

\section{CNS tool development}

According to Diederen and Jonkers (2001), it is the ultimate goal of CNS is to develop solutions for problems that are encountered in real-life organisational arrangements. These solutions take the form of 'tools', generic instruments to tackle specific types of real-world practical problems. Tools for design, construction and governance aim at facilitating the implementation of technological innovations; tools for enabling processes of communication and change aim at social and organisational aspects of innovation. Network business redesign always involves intricate combinations of technological and organisational aspects of co-operation. Chain and network designs ideally provide for sufficient flexibility, such that there is room for adaptation to changing circumstances and for further development. Network design and redesign trajectories may be implemented as iterative innovation cycles of technological and organisational aspects, increasing network performance step by step.

The main objectives in this regard of CNS can be categorised as follows:

- increasing responsiveness and flexibility, optimising the ability to react to changes in consumer demand, for instance through information exchange on stocks and flows of products and through optimising these stocks and flows;

- concerted process innovation, optimising the flow of technical transformations, for instance through standardisation of components or packaging and through improved logistics;

- concerted product innovation and market development, optimising the ability to exploit new market opportunities, for instance through joint product development;

- capturing side-effects, managing and controlling effects of production activities on the environment and on public opinion (aspects of quality of the production process); taking on social responsibilities and dealing with societal values and ethical concerns.

It is in the development of tools that scientists and innovators meet. Above, we distinguished between technical tools for design and construction and social tools for communication and co-ordination. Table 2 refines this categorisation of tools by distinguishing also between the purposes of tools (problem categories). The distinction between technical and social tools is presented on the vertical axis and the main problem categories on the horizontal axis. The cells present the tools that are being developed with contributions from both sides, deductively from the side of research and inductively from the side of business.

\section{Concluding remarks}

This description of the knowledge domain of CNS is a starting point, a first attempt to define and delineate this new multidisciplinary field of research, a first step in structuring current thought on chains and networks and in identifying future development paths. As new CNS knowledge is 





Table 2. The CNS problem areas and types of tools (Diederen and Jonkers, 2001).

\begin{tabular}{|c|c|c|}
\hline & $\begin{array}{l}\text { Technical tools: } \\
\text { Design and construction }\end{array}$ & $\begin{array}{l}\text { Social tools: } \\
\text { Communication and co-ordination }\end{array}$ \\
\hline Responsiveness & tools for: & tools for: \\
\hline Reacting rapidly to consumer demand & $\begin{array}{l}\text { - data processing: tracing and tracking } \\
\text { - stock and flow monitoring } \\
\text { - planning of production, storage and } \\
\text { transport }\end{array}$ & $\begin{array}{l}\text { - information sharing } \\
\text { - risk sharing } \\
\text { - contracting } \\
\text { - trust building } \\
\text { - benchmarking }\end{array}$ \\
\hline Process innovation & tools for: & tools for: \\
\hline Optimising the production system & $\begin{array}{l}\text { - logistic optimisation } \\
\text { - standardising interfaces }\end{array}$ & $\begin{array}{l}\text { - organising joint investments } \\
\text { - joint process development and } \\
\text { innovation management }\end{array}$ \\
\hline Product innovation & tools for: & tools for: \\
\hline Exploiting market opportunities & $\begin{array}{l}\text { - market communication } \\
\text { - joint product launching }\end{array}$ & • joint product development \\
\hline Externalities & & tools for: \\
\hline Capturing side effects & & $\begin{array}{l}\text { - inter-firm communication } \\
\text { - fostering acceptance of social } \\
\text { responsibilities } \\
\text { - image and goodwill building } \\
\text { - public-private co-operation }\end{array}$ \\
\hline
\end{tabular}

generated in both inductive and deductive efforts, as new engineering perspectives open up, and new approaches from alternative theoretical vantage points are attempted and explored, the crude outlines presented in this editorial paper will be expanded and refined. In an interdisciplinary field like this, where so many additions to knowledge come forth in a piecemeal manner from all sides, it is of crucial importance to bring these new pieces of knowledge and experience together, while keeping an overview of the domain's whole structure as it develops. To do so, facilities have to be created and procedures put in place, that deal with the further development and expansion of the overall knowledge base as delineated in this domain description. We strongly feel that although considerable progress has been made over the past couple of years in the development of CNS, a number of important and exciting challenges are still waiting to be tackled.

In this editorial we have presented a model for CNS developed by Diederen and Jonkers (2001). In the next issues we will introduce other models to further enrich the discussion on object and scope of CNS.

\section{Contents of this issue and management implications}

JCNS intends to be a virtual platform in which scientists meet with business managers to exchange the latest ideas and concepts on chains and networks. An overview of the managerial implications of the different contributions in this second issue is given below.

The first article of this issue, by Hornibrook and Fearne, analyses the impact of uncertainty on contractual relationships in the supply chain. Due to recent incidents, food supply chains have to deal with more risk and costs associated with food safety and quality requirements. The case of the UK beef supply chain demonstrates that increasing risk has a significant impact on contracts all along the supply chain; in general, emphasis is shifting from outcome-based contracts towards behaviour-based contracts. An interesting aspect of this study is the role of subjective information on the behaviour of actors in the chain and the importance of personal relationships in each dyad of the chain. It is revealed that formal objective 
information as used in quality assurance programmes is effective in reducing risk within the chain, e.g. at retailers, however this is far less the case at the level of the consumer. From the analysis of the transaction costs involved in supply chain risks, the authors conclude that the market offers greater incentives to meet food safety and quality standards than public policy can.

The second article, by Kemp and Gauri, is about the factors that determine the performance of a joint venture. It appears that, in contrast to expectations, differences in dependency between partners in a joint venture do not necessarily have a negative effect on the performance of a joint venture. This is interesting because most managers are reluctant to start a joint venture with a dependent partner, because they presume that conflicts may arise more readily with such a partner. The article shows that the threat of conflict due to asymmetry in dependency is compensated by the norms of exchange shared by the partners. Therefore, the authors recommend that firms manage the dependency position in a joint venture by investing time and effort in discussing the norms of exchange up-front in order to develop trusting relationships between the partners.

The third article, by Fynes et al., looks into the interface of quality management and buyer-suppliers relationships. The study conducted in the electronics industry has implications for both operations and marketing managers. First, they should recognise the important role of quality design in the overall spectrum of quality performance. Quality interpreted as 'meeting the specification' is regarded as an 'order-qualifier', whereas quality implemented in the design is called an 'order-winner'. Second, obtaining design quality a strong supplier-buyer relationship has to be developed,- involving trust and commitment, and a willingness to adapt to each other's needs in a flexible way. Especially in situations involving complex product and process technology, customers need to consider strong linkages with their suppliers in their product development.

The fourth article in this issue, by Hagen and Hayashi, deals with the development of new network structures. In the transfer of goods from a manufacturer to a multi-unit retailer, there are various alternatives for the provision of warehousing and distribution functions. In an in-depth case study analysis, a description is given of the recent evolution of a distribution network function for ice cream in Japan and the forces behind these processes are explored. The study reveals the most important mechanisms that appear to have helped ice cream manufacturers trust their competitors to build a joint distribution network. It describes how the relation between manufacturers and their dedicated wholesalers changed. Detaching from the wholesalers, turned out to be an enabler for building up trust between the competing manufacturers. It was also shown that the features of the unified distribution arrangement and the changed nature of stock ordering and shelf planning enabled the manufacturers to co-operate with their competitors.

In the fifth article in this issue Skytte and Blunch report on an extensive international survey among retail buyers on their judgement of, and vendor attributes of, suppliers for some food products. The research shows that the traditional four Ps are losing ground to some attributes that are often neglected. The demand for traceability implies that producers must be able to provide information on a wide range of issues on the history of the product. To guarantee the quantities that are needed, suppliers are judged on their ability to develop horizontal co-operation with other suppliers. Suppliers are also more frequently assessed on their ability to deal with the issue of vertical co-operation with retailers. To develop long-term relationships with retailers, some suppliers- have to drastically change their attitudes about how to do business. A remarkable conclusion of the study is that retailers in Western Europe do not have significantly different attributes; it seems that it may be easier to export within the European market than was previously thought.

\section{References}

Christopher, M.G., 1998, Logistics and Supply Chain Management; Strategies for reducing costs and improving services, Pitman Publishing, London.

Clemons, E.K. and M.C. Row, 1992, Information technology and industrial cooperation: the changing economics of coordination and ownership, Journal of Management Information Systems, 9, (2), 9-28.

Cooper, M.C., D.M. Lambert and J.D. Pagh, 1997, Supply Chain Management: more than a new name for logistics, International Journal of Logistics Management, 8 (1), 1-14.

Diederen, P.J.M. and H.L.Jonkers, 2001, Chain and network studies, KLICT Working Papers, www.KLICT.org (Go to "projecten"; scroll to "working papers").

Freeman, C., 1990, The Economics of Innovation, Edward Elgar, Aldershot.

Jonkers, H.L., H.W.J. Donkers and P.J.M. Diederen, The knowledge domain of chain and network studies, KLICT Working Papers, www.KLICT.org (Go to "projecten"; scroll to "working papers").

Lambert M.D. and M.C. Cooper, 2000, Issues in supply chain management, Industrial Marketing Management, 29, 65-83.

Lazzarini, S.G., F.R. Chaddad and M.L. Cook, 2001, Integrating supply chain and network analyses: the study of netchains, Journal on Chain and Network Science, 1 (1), 7-22. 
Omta S.W.F., J.H. Trienekens and G. Beers, 2001, Chain and network science: a research framework, Journal on Chain and Network Science, 1 (1), 1-6.

Powell, W.W., 1990, Neither market nor hierarchy: network forms of organisation, Research in Organisational Behaviour, 12, 295336.

Sawhney M, and D. Parikh, 2001, Where value lives in a networked world, Harvard Business Review, January, 79-86.

Stevens, 1989, Integrating the supply chain, International Journal of Physical Distribution \& Materials Management, 19 ( 8), 3-8.

Stoneman, P., 1995, Handbook of economics of technological change.

Thompson, J.D., 1967, Organisations in Action: Social Science Bases of Administrative Theory, McGraw-Hill, New York.

Venkatraman, N., 1994, IT-enabled business transformation: from automation to business scope redefinition, Sloan Management Review, 35, Winter, 73-87.

Wasserman, S. and K. Faust, 1994, Social network analysis: Methods and applications, University of Cambridge Press, Cambridge, Mass. 